\title{
Mensaje editorial
}

En el presente número de la Revista, el último del año 2006, incluimos una variedad de artículos que es, o debiese ser, del interés de nuestros lectores. Abordan temas que van desde el análisis de la tendencia de tasas de mortalidad por tumores cerebrales malignos en nuestro país, hasta una detallada caracterización de la transferencia y contratransferencia que puede ocurrir en la atención de personas que han sido víctimas de incesto. Además de estos temas, que son marcadamente específicos para al gunas de las especialidades que conforman nuestra Sociedad, publicamos dos artículos que alcanzan transversalmente a materias que importan a todos nuestros miembros. El primero de ellos es una editorial que da cuenta de un esfuerzo de capacitación realizado en el Servicio de Salud M etropolitano Sur, dirigido a formar a la red de prestadores del servicio público en la atención del accidente cerebrovascular, patología que se encuentra incluida desde el presente año en el listado de garantías explícitas que establece la reforma al sistema de salud que se está implementando en nuestro país. Una especial mención merece, entre los muchos aspectos encomiables de esta iniciativa, su carácter incluyente, que contempló a las distintas regiones de nuestro país, desde la Región XV, de Arica y Parinacota (novedad a la que deberemos acostumbrarnos a partir del presente año), hasta la región XII, de Magallanes y, quizás más importante aún, incluyó a la red de prestadores de atención primaria al interior del propio servicio de salud. El éxito en la implementación de esta esperada y discutida reforma descansa, en buena medida, en el esfuerzo de capacitación de la red asistencial, que encuentra en el modelo y las enseñanzas derivadas de esta experiencia, un excelente ejemplo. Nuestra Sociedad ha colaborado, a través de su grupo dedicado al estudio de la enfermedad cerebrovascular, tanto a la elaboración de la guía clínica como a la elaboración de programas de educación continua en esta materia. Esperamos que la editorial que publicamos a continuación alimente un intercambio de opiniones respecto a esta materia, que recoja lo mejor de estas experiencias. Opiniones son bienvenidas, del mismo modo, respecto al resto de los artículos publicados en este número y, muy particularmente, respecto a la reflexión ética que cierra el volumen. En ésta se aborda una materia que afecta, transversalmente, a las tres especialidades que participan en nuestra Sociedad. La capacidad de auto-regulación que la profesión médica ha demostrado en el manejo de los conflictos de intereses derivados de su relación con la industria ha sido considerada insuficiente por otros actores. En un modelo de práctica de nuestra profesión en que la puerta ha sido abierta (aunque no por nosotros) para que numerosos otros actores intervengan en la decisión médica, parece aún ser tiempo para que al interior de nuestras agrupaciones profesionales reflexionemos y propongamos soluciones para un estado de cosas que, tal como es relatado en el artículo que publicamos en este número, parece preocupante. En países desarrollados esta auto-regulación de la profesión médica ha llegado a la par de la elaboración de códigos de conducta, precisos y transparentes, propuestos por la industria farmacéutica y, más notoriamente, de leyes compulsivas que intervienen sobre la forma como esta relación entre la industria y el profesional que prescribe medicamentos o dispositivos médicos se establece.

El Editor 